\title{
Análise de Decisão Multicritério para a Gestão de Concessionárias de Distribuição de Energia Elétrica
}

\section{Multicriteria Decision Analysis for the Management of Concessionaires of Electricity Distribution}

Fernanda Carvalho Lima Santos ${ }^{1}$, Antonio Campos Monteiro Neto ${ }^{1}$, Roberto Stefan Fernandes de Aguiar ${ }^{1}$, Patrícia Guarnieri $^{2}$, André Luiz Marques Serrano ${ }^{2}$

${ }^{1}$ Agência Nacional de Energia Elétrica.

${ }^{2}$ Universidade de Brasília.

\section{NFO ARTIGO}

\section{Palavras-chave:}

Observatório Social,

Controle Social,

Contabilidade,

Accountability.

\begin{abstract}
RESUMO
Como forma de incentivar as empresas a melhorarem continuamente, a Agência Nacional de Energia Elétrica (ANEEL) divulga, periodicamente, rankings sobre o desempenho das concessionárias de distribuição dos serviços de energia elétrica de acordo com diversos indicadores. De forma a integrar diferentes pontos de vista, este trabalho visa a ordenar as concessionárias de acordo com o risco de perda de capacidade operacional e econômico-financeira. Trata-se de uma pesquisa aplicada, descritiva, qualiquantitativa, cujo procedimento técnico é a modelagem multicritério, proveniente da Pesquisa Operacional. Nela foi aplicado o método Promethée (Preference Ranking Organization METHod for Enrichment of Evaluations) para ordenar as alternativas mediante o conjunto de critérios definido. $\mathrm{O}$ processo de elicitação foi conduzido com decisores das unidades organizacionais da ANEEL, por meio de entrevistas e a obtenção de dados também se baseou em análise documental. O principal resultado é a criação de ranking baseado em diversos indicadores, que pode ser usado para identificar antecipadamente as empresas do setor de distribuição de energia que estão com a situação operacional e econômico-financeira degradada.

A B S T R A C T

As a way to encourage companies to continually improve their performance, the Agência Nacional de Energia Elétrica (ANEEL) publishes, periodically, rankings on the performance of distributors of electric energy services according to various indicators. In order to integrate different points of view, this paper aims at ranking the distributors of electric energy according to the risk of loss of operational and economic-finance capacity. Thus, it was performed an applied and descriptive research, based in qualitativequantitative approach. We use the multicriteria modeling, from Operational Research, in the context of decision-making on ranking of concessionaries of electric energy, specifically the Promethèe (Preference Ranking Organization METHod for Enrichment of Evaluations). To this end, we applied the Promethée method. The elicitation process was conducted with decision makers from organizational units of Aneel, through interviews and documental analysis.
\end{abstract}

ARTICLE INFO

Keywords:

Social Observatory, Social Control, Accountancy, Accountability.

\footnotetext{
* Correspondência para autor:

fernandacarvalho@aneel.gov.br (Santos ,F.C.L.), acampos@aneel.gov.br (Monteiro Neto, A.C.), robertostefan@aneel.gov.br (de Aguiar, R.S.F.), patguarnieri@gmail.com (Guarnieri, P.), andrelms.unb@gmail.com ( Serrano, A.L.M.).
}

DOI: doi.org/10.21714/1679-1827-2020.v18.n1.p82-102

1679-1827 (C) 2019 Gest@o.org. 


\section{Introdução}

O procedimento para se chegar ao preço justo pela energia elétrica tem por base o conceito de modicidade tarifária. A modicidade tarifária existe pelo fato de ter o Estado a obrigação de garantir à coletividade o acesso ao serviço público com "regularidade, continuidade, eficiência, segurança, atualidade, generalidade, cortesia na sua prestação e modicidade de tarifas" (GONÇALVES, 2013).

Para propiciar níveis mínimos de qualidade da energia usada pelos consumidores, a ANEEL estabelece limites para indicadores de qualidade que, se descumpridos, obrigam as concessionárias a compensarem financeiramente os consumidores. Esse tipo de penalização, num contexto de mau desempenho crônico da empresa, tende a piorar ainda mais a situação, agravando o prejuízo para a sociedade devido à prestação deficiente do serviço de distribuição de energia elétrica. Por esse motivo, em casos excepcionais, a ANEEL ameniza temporariamente a carga regulatória para que a empresa possa se recuperar e voltar a prestar um serviço com qualidade adequada aos consumidores.

A decisão da Agência Reguladora Aneel leva em conta uma série de fatores. É preciso avaliar o desempenho financeiro das empresas, a percepção que os consumidores e o seu desempenho técnico e operacional, por meio de indicadores que a ANEEL já contabiliza, abrangendo aspectos qualitativos e quantitativos. Essas avaliações, no entanto, são normalmente restritas a um determinado critério.

A fim de elaborar um ranking considerando múltiplos critérios, a abordagem mais adequada é a de Apoio Multicritério à Decisão (AMD). Segundo Jannuzzi (2009), a abordagem AMD tem um grande potencial de aplicação nos processos decisórios no setor público, nos quais as decisões precisam estar baseadas em critérios técnicos objetivos e transparentes, aliados a juízos de natureza política e subjetiva dos gestores políticos envolvidos. Ela consiste em um conjunto de métodos e técnicas para auxiliar ou apoiar pessoas e organizações a tomarem decisões, sob a influência de uma multiplicidade de critérios (GOMES, 2014).

Ao permitir a incorporação de pontos de vista contraditórios, a AMD presta auxílio ao gestor na decisão de problemas diante do desafio regulatório. Almeida (2013) nos esclarece que essa abordagem consiste em analisar a adoção ou não de determinada ação, em análise dos critérios positivos e negativos de sua implementação, em dois pilares. A partir da base, os critérios são confrontados em função do grau de importância, utilizando o procedimento para eliminação de argumentos positivos e negativos, até o ponto em que fique claro que qual pilar possui maior peso.

No caso em estudo, a aplicação da AMD se justifica pela diversidade das informações disponíveis, compreendendo indicadores de desempenho técnicos, operacionais, sociais, econômicos e financeiros, abrangendo assim fatores qualitativos e quantitativos. Assim como considera a multiplicidade de atores envolvidos na tomada de decisão - a Diretoria colegiada da ANEEL, subsidiada pelas superintendências. O presente trabalho aborda a detecção de empresas distribuidoras de energia elétrica cuja situação econômicofinanceira e a qualidade do serviço estejam de tal forma degradadas que o cumprimento das regras vigentes de ressarcimento aos consumidores as impossibilitem de realizar investimentos na melhoria da própria rede de distribuição.

É importante enfatizar que esta detecção ocorre em boa parte das vezes após um longo período de degradação da situação econômico-financeira da empresa, sendo o problema tratado usualmente pela ANEEL com intervenções e, em situações extremas, com pedidos de recuperação judicial. Nesse ínterim, a qualidade do serviço também se degrada, trazendo grande prejuízo para os consumidores, sejam residenciais, comerciais ou industriais. É, portanto, de altíssimo interesse público que a Agência tenha capacidade de se antecipar a esse tipo de problema e de tomar medidas preventivas capazes de evitar situações extremas.

Para agir de forma proativa nessas situações e evitar a degradação da qualidade do fornecimento de energia elétrica, é necessário identificar as empresas nas quais a qualidade do fornecimento começa a trajetória de decadência, e relacionar essa tendência a eventuais dificuldades de ordem econômico-financeira. Devem fazer jus ao ajuste de conduta apenas o grupo de empresas em pior condição, não todas. Por permitir o ordenamento das empresas distribuidoras de energia elétrica de acordo com critérios qualitativos $\mathrm{e}$ quantitativos, o método AMD é típico para a resolução deste problema.

Alguns artigos ao longo dos anos, tem abordado o uso da decisão multicritério no setor energético. Alguns desses trabalhos são destacados aqui. Fittipaldi et al. (2000) estudaram a comercialização de energia 
elétrica com base no MAUT. Zambon et al. (2005) estudaram a análise de decisão multicritério na localização de usinas termoelétricas. Silva e de Almeida (2007) utilizaram os métodos SMARTS e SMARTER para desenvolver um modelo de ordenação de pontos monitorados de um sistema elétrico

Mais recentemente, Garcez e de Almeida (2013) realizaram a avaliação de risco multidimensional de sistemas subterrâneos de distribuição de energia elétrica com base no MAUT. López e de Almeida (2014) utilizaram o método PROMETHEE V para desenvolver um modelo de seleção de projetos vindos do planejamento estratégico de uma empresa do setor elétrico brasileiro. Macedo et al. (2014) usaram o método ELECTRE TRI para a classificação para a substituição de motores industriais visando a eficiência energética. Clemente et al. (2015) apresentaram a aplicação do método PROMETHEE-ROC na priorização de tecnologias críticas para a geração de energia. Bonatti e Baracho (2015) utilizaram o método AHP na gestão da informação e processo decisório no setor energético.

No entanto, não se encontrou nenhum artigo que trate da adoção de métodos multicritério no contexto da regulação do setor energético. Assim, o objetivo desse artigo é ordenar as concessionárias de distribuição de energia de acordo com o risco de perda de capacidade operacional e econômico-financeira. Para atingir o objetivo geral, foi necessário: i) identificar os principais critérios de avaliação econômico-financeira e social; ii) identificar as principais alternativas de atuação a fimm de evitar situações de excepcionalidade; iii) identificar a racionalidade do processo decisório; e iv) desenvolver a modelagem multicritério com base nas problemáticas de ordenação e classificação das concessionárias de distribuição de acordo com o risco de perda a fim de direcioná-las para ações pertinentes e evitar situações de excepcionalidade.

A modelagem proposta possibilitou identificar as empresas que possuem situação mais crítica considerando os critérios e parâmetros definidos nas entrevistas com os decisores. $\mathrm{O}$ trabalho limitou-se a ordenar as empresas, visto que a classificação em faixas de risco traria uma dificuldade de definição dos limites entre as classes, pois os casos de flexibilização regulatória são raros, o que pode levar a uma grande imprecisão.

Esse artigo abrange, além da presente introdução, a seção 2 que trata da abordagem AMD, método Promethèe e do uso dos métodos multicritério no setor energético. A seção 3 detalha os métodos e técnicas de pesquisa, com a descrição detalhada dos procedimentos utilizados para conduzir o estudo. A seção apresenta, analisa e discute os resultados encontrados e, por fim, a seção 5 apresenta as considerações finais, limitações e sugestões para estudos futuros.

\section{Referencial Teórico}

\subsection{Abordagem de Apoio Multicritério à Decisão (AMD)}

Um problema de decisão multicritério tem, pelo menos, duas alternativas a escolher e dois critérios, além do critério mais comumente usado, que é o custo. A escolha das alternativas advém da necessidade de se atender múltiplos objetivos que normalmente são conflitantes entre si. O Apoio Multicritério a Decisão AMD, ou MCDA (Multiple Criteria Decision Aid) objetiva fornecer aos decisores um conjunto de ferramentas que os permite chegar a decisões baseadas em pontos de vista diferentes (GUARNIERI, 2015).

A abordagem AMD tem como princípio básico tentar estabelecer uma relação de preferências (subjetivas) entre alternativas a serem avaliadas, priorizadas, ordenadas sob a influência de vários critérios (GOMES, 2014). Este autor sustenta que a abordagem multicritério tem como característica considerar que $(i)$ os processos decisórios são complexos e existem vários atores envolvidos, e são atores que definem os aspectos relevantes no processo de decisão; (ii) cada ator tem a sua subjetividade (juízo de valores); (iii) reconhece os limites da objetividade e consideram as subjetividades dos atores, e (iv) tem como pressuposto que o problema de decisão, de um modo geral, não está claramente definido e nem bem estruturado.

As fases usuais da abordagem AMD são: (i) Identificação do problema: é a fase em que todos os atores devem ter o entendimento comum do problema, objetivos, decisões a serem tomadas, e critérios pelos quais as decisões serão julgadas e avaliadas; (ii) Construção e uso do modelo: é o desenvolvimento formal das preferências do decisor, valorar trade-offs, metas, e então comparar e relacionar cada uma das ações de maneira sistemática e transparente; e (iii) Desenvolvimento de planos de ação: é a implementação de resultados, traduzindo a análise em planos específicos de ação (BELTON e STEWART, 2002). Basicamente se divide em três abordagens, são descritas conforme o Quadro 1. 
Quadro 1. Abordagens de avaliação multicritério.

\begin{tabular}{|c|c|}
\hline Abordagem & Decisão \\
\hline $\begin{array}{l}\text { Teoria da Utilidade } \\
\text { Multiatributo ou do } \\
\text { Critério Único de } \\
\text { Síntese }\end{array}$ & $\begin{array}{l}\text { Deriva-se da corrente de pensamento americana, as preferências do decisor por determinada } \\
\text { alternativa, quando a avalia mediante um conjunto de critérios ou indicadores, são agregadas em } \\
\text { um valor de utilidade único, que é mensurado de uma forma aditiva (com trade-offs), ou seja, é é } \\
\text { gerado um score de cada alternativa com base no desempenho que apresentou em cada critério, } \\
\text { assim as alternativas melhor avaliadas são as que obtiverem maior score (ALMEIDA, 2011). } \\
\text { Alguns métodos desta abordagem podem ser citados: MAUT, SMART, TOPSIS, AHP. }\end{array}$ \\
\hline $\begin{array}{l}\text { Sobreclassificação } \\
\text { ou Subordinação }\end{array}$ & $\begin{array}{l}\text { Derivada da corrente francesa, o principal objetivo é a construção de relações binárias que } \\
\text { representem as preferências do decisor com base na informação disponível (sem trade-offs) entre } \\
\text { critérios, neste caso, não se obtém um score das alternativas mediante seu desempenho em cada } \\
\text { critério (LÉGER \& MARTEL, 2002). Por meio de uma comparação par a par, verifica-se qual } \\
\text { alternativa é superior em cada critério, estabelecendo-se uma relação de superação no confronto } \\
\text { entre duas alternativas. Assim, é melhor avaliada a alternativa que apresentar superioridade na } \\
\text { maioria dos critérios, esta abordagem é baseada no sistema de eleição de Condorcet e é } \\
\text { considerada uma abordagem mais equilibrada, tendo em vista que é escolhida a alternativa que } \\
\text { possuir um desempenho satisfatório na maioria dos critérios, segundo ALMEIDA (2013). Os } \\
\text { principais métodos desta abordagem são os das famílias: ELECTRE, PROMETHEE. }\end{array}$ \\
\hline Métodos Interativos & $\begin{array}{l}\text { São desenvolvidos principalmente no âmbito da Multi-objective Linear Programing (MOLP), os } \\
\text { quais se caracterizam por possuir passos computacionais e serem interativos, permitindo trade- } \\
\text { offs (LÉGER \& MARTEL, 2002). Os métodos da MOLP buscam uma alternativa que seja } \\
\text { claramente superior em todos os objetivos estabelecidos (dominante), para isso, efetuam a } \\
\text { agregação das preferências dos decisores e cálculos matemáticos, interativos e sucessivos, } \\
\text { avaliação destas soluções, de possível alteração da estrutura de preferências em face da nova } \\
\text { informação disponível, com vista à convergência para uma solução final que estabeleça um } \\
\text { compromisso aceitável entre as funções objetivo (ANTUNES \& ALVES, 2012). Cabe ressaltar } \\
\text { que esse processo é diferente das abordagens do critério único de síntese e de sobreclassificação, } \\
\text { as quais, mediante comparação entre critérios, buscam a solução mais satisfatória e não a } \\
\text { dominante (ALMEIDA, 2011). Alguns métodos dessa abordagem podem ser citados: STEM, } \\
\text { TRIMAP, ICW, PARETO RACE (ANTUNES \& ALVES, 2012). }\end{array}$ \\
\hline
\end{tabular}

Fonte: Guarnieri (2015).

Guarnieri (2015) relata que a escolha das abordagens expostas no Quadro 1, depende da racionalidade do decisor ao demonstrar suas preferências. A racionalidade pode ser aditiva, em que o desempenho das alternativas é avaliado quantitativamente (valores numéricos) ou qualitativamente (escalas). A racionalidade não aditiva caracteriza-se pela avaliação de preferência (forte, fraca, indiferença, incomparabilidade) das alternativas em pares pelas relações.

Adicionalmente, conforme Guarnieri (2015), a situação do problema também influencia a escolha do método mais adequado para a relação multicritério. As decisões que envolvem o contexto multicritério podem ser direcionadas para várias problemáticas, a escolha, que significa reduzir a um conjunto menor o número de alternativas existentes, a ordenação, que significa ordenar as alternativas em ordem crescente ou decrescente, e a classificação, que significa categorizar as alternativas em grupos por similaridade, de forma categórica ou ordenada.

Neste trabalho convencionou-se a utilização do método PROMETHEE, proveniente da abordagem de sobreclassificação ou, na língua inglesa, outranking, tendo em vista ser o mais adequado às características do problema de decisão envolvido, que se caracteriza como de ordenação, bem como é não compensatório. Assim, a próxima seção se destina a apresentar as principais características desse método.

\subsection{Método Promethée}

Brans e Mareschal (2002) relatam que os métodos da família Promethée (Preference Ranking Organization Method for Enrichment Evaluation) possuem dois pilares principais. São eles: a construção da relação de sobreclassificação (outranking) conjugando informação entre alternativas e critérios; e estudo dessa relação para apoio à decisão. Conforme de Almeida (2013) esta família de métodos produz uma relação de sobreclassificação em valores, os quais têm interpretação física ou econômica facilmente entendidas pelo decisor. O mesmo autor descreve a estrutura de avaliação dos métodos Promethée, conforme a seguir.

Um peso $p_{j}$, que reflete importância, é definido para cada critério pelo decisor. Com os pesos definidos é possível obter o grau de sobreclassificação de $a$ sobre $b$ para cada par de alternativas $(a, b)$, conforme segue: 


$$
\pi(a, b)=\sum_{i=1}^{n} p_{i} f_{i}(a, b)
$$

(Fórmula 1)

Onde:

$$
\sum_{i=1}^{n} p_{i}=1
$$

A função da diferença $|g(a)-g(b)|, F(a, b)$, é então definida entre o desempenho das alternativas para cada critério $i$. É possível exemplificar da forma mais simples: $F_{i}(a, b)=1$ quando $g(a)>g(b)$; caso contrário, $F_{i}(a, b)=0$. Ou seja, o grau de sobreclassificação $\pi(a, b)$ terá em sua composição o peso $p_{i}$ de cada critério $i$, para o qual a alternativa ' $a$ ' tenha melhor desempenho do que ' $b$ ' (de ALMEIDA, 2013).

Quando o problema envolve limiares de indiferença ou de preferência ou ambos, a função $F_{i}(a, b)$ pode ser definida de acordo com outros modelos. Portanto, $F_{i}(a, b)$ pode ser definida de acordo com o modo como a preferência do decisor aumenta com a diferença entre o desempenho das alternativas para cada critério $\mid g_{j}(a)$ - $g_{j}(b) \mid$, e assume valores entre 0 e 1 . O valor de $F_{j}(a, b)$ aumenta se a diferença de desempenho, ou a vantagem de uma alternativa em relação à outra, aumenta; e é igual a zero se o desempenho de uma alternativa é igual ou inferior ao da outra (de ALMEIDA, 2013).

Definida a função $F_{j}(a, b)$, estabelecidas as intensidades de preferências e obtido o grau de sobreclassificação, as alternativas são ordenadas em ordem crescente de $\Phi+(a)$ e ordem crescente de $\Phi-(a)$.

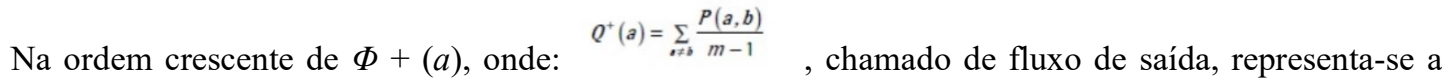
intensidade de preferência de $a$, sobre todas as alternativas. Quanto maior $\Phi+(a)$, melhor a alternativa. $\mathrm{Na}$ ordem decrescente de $\Phi-(a)$, onde: $Q^{-}(a)=\sum_{* \neq b} \frac{P(b, a)}{m-1} \quad$, chamado de fluxo de saída, representa-se a intensidade de preferência de todas as outras alternativas sobre a. quanto menor $\Phi-(a)$, melhor a alternativa (de ALMEIDA e COSTA, 2003).

Brans e Mareschal (2002) descrevem os seis métodos da família PROMETHEE.

\begin{tabular}{|c|c|}
\hline Método & Descrição \\
\hline PROMETHÉE I & $\begin{array}{l}\text { Consiste no fato de que a interseção entre os fluxos estabelece uma relação de sobreclassificação } \\
\text { parcial entre as alternativas. }\end{array}$ \\
\hline PROMETHÉE II & $\begin{array}{l}\text { classifica as alternativas, estabelecendo uma ordem decrescente de } \Phi(a)=[\Phi+(a)]-[\Phi-(a)] \text { (fluxo } \\
\text { líquido), e estabelece uma ordem completa entre as alternativas. }\end{array}$ \\
\hline $\begin{array}{l}\text { PROMETHÉE III } \\
\text { e IV }\end{array}$ & $\begin{array}{l}\text { tratam problemas de decisão mais sofisticados. PROMETHEE IV envolve o caso de um conjunto de } \\
\text { ações A que surge quando as ações são, por exemplo, porcentagens, dimensões de um produto. }\end{array}$ \\
\hline PROMETHÉE V & $\begin{array}{l}\text { é utilizado quando, após estabelecer a ordem completa das alternativas (PROMETHEE II), são } \\
\text { introduzidas restrições identificadas no problema para as alternativas selecionadas. }\end{array}$ \\
\hline PROMETHÉE IV & $\begin{array}{l}\text { é utilizado quando o decisor não está apto ou não quer definir precisamente os pesos para os } \\
\text { critérios. Assim, se podem especificar intervalos de possíveis valores em vez de um valor fixo para } \\
\text { cada critério. }\end{array}$ \\
\hline
\end{tabular}

Quadro 2. Métodos da Família Promethée

Fonte: Brans e Mareschal (2002)

Para cada problemática de decisão um dos métodos é indicado. A próxima seção aborda a aplicação de métodos multicritério no setor energético.

\subsection{A utilização da AMD no setor energético}

A utilização da abordagem AMD no setor energético brasileiro ocorre desde o ano 2000, com alguns trabalhos científicos que trouxeram importantes resultados para o setor, assim a seguir destaca-se aqui os principais estudos. Fittipaldi et al. (2000) já consideravam a comercialização de energia elétrica no mercado competitivo, recente para a época, como um problema que poderia ser avaliado com base em múltiplos critérios, utilizando a Teoria da Utilidade Multiatributo (MAUT).

Zambon et al. (2005) estudaram a análise de decisão multicritério na localização de usinas termoelétricas utilizando Sistemas de Informação Geográfica. O problema analisa as alternativas de potenciais 
locais para instalação de usinas termoelétricas considerando fatores econômicos e ambientais. Assim, demonstra a aplicabilidade das técnicas multicritério no planejamento da expansão do setor elétrico.

Silva e de Almeida (2007) utilizaram os métodos SMARTS (Simple Multi-attribute Rating Technique using Swings) e SMARTER (Simple Multi-attribute Rating Technique Exploiting Ranks) da teoria da utilidade multiatributo para desenvolver um modelo de ordenação de pontos monitorados de um sistema elétrico, baseado no nível de qualidade da energia elétrica relativa aos fenômenos dos afundamentos de tensão.

López e de Almeida (2014) utilizaram o método PROMETHEE V para desenvolver um modelo de seleção de projetos vindos do planejamento estratégico de uma empresa do setor elétrico brasileiro para compor o portfólio da organização. Schmitz et al. (2016) estudaram a estratégia energética e socioambiental na gestão pública com aplicação dos métodos AHP e PROMETHEE. Os autores utilizaram estes métodos para elaborar um modelo de tomada de decisão pública para a expansão estratégica da matriz energética do Rio Grande do Sul.

Garcez e de Almeida (2013) realizaram a avaliação de risco multidimensional de sistemas subterrâneos de distribuição de energia elétrica. Os autores propõem um modelo multicritério de avaliação de risco por meio da teoria da decisão e da teoria da utilidade multiatributo (MAUT). Macedo et al. (2014) estudaram o método ELECTRE TRI para obtenção de um modelo de classificação para substituição de motores industriais em uma empresa do setor químico para alcance de eficiência energética. $O$ caso foi acionado pois foi estabelecida lei que fornece níveis máximos de utilização de energia.

Clemente et al. (2015) apresentaram a aplicação do método PROMETHEE-ROC na priorização de tecnologias críticas para a geração de energia. O método auxilia nos problemas de decisão em que há muitos fatores, com diferentes níveis de complexidade envolvidos. Assim é o caso do setor elétrico, com a presença de fatores sociais, políticos, ambientais e governamentais. Bonatti e Baracho (2015) utilizaram o método AHP (Analytic Hierarchy Process) para a mensuração de critérios e alternativas na gestão da informação e processo decisório no setor energético. A pesquisa fundamentou-se na necessidade de identificação do fluxo de informação para as tomadas de decisão nas concessionárias energéticas.

\section{Métodos e técnicas de pesquisa}

O presente trabalho é uma pesquisa aplicada, descritiva e quali-quantitativa. O procedimento técnico utilizado foi a modelagem multicritério, proveniente da Pesquisa Operacional, a qual prevê alguns passos: i) Definição do problema; ii) Definição de critérios; iii) Definição de alternativas; iv) Definição dos parâmetros do modelo; v) Definição do método a ser utilizado; vi) Aplicação do método; vii) Análise de sensibilidade (Guarnieri, 2015; Cinelli et al., 2020). A coleta de dados, que na modelagem multicritério é denominada 'elicitação', e ocorre a fim de verificar a percepção dos decisores e o julgamento dos valores das alternativas mediante um conjunto de critérios, ocorreu por meio de entrevista com 4 gestores de superintendências da empresa ANEEL que atuam na regulação de concessionárias de energia elétrica, conforme descrito no Quadro 2. Além disso, por meio da análise documental foram consultados todos os processos de tratamento de pedidos de socorro feitos à Aneel em 2016, devido a dificuldades técnico-operacionais e financeiras, autuadas nos respectivos processos de termo de ajuste de conduta. A partir do universo de 62, a amostra foi composta por 10 concessionárias, sendo 5 de grande porte e 5 de pequeno porte. A limitação a 10 ocorreu em função de limitações do software Promethée na versão acadêmica (gratuita). Tais documentos estão disponíveis na ANEEL e sua fundamentação é também apresentada no Quadro 2: 
Quadro 2 - Os rankings das empresas de distribuição de energia elétrica estabelecidos pela ANEEL.

\begin{tabular}{|l|l|l|l|}
\hline \multicolumn{1}{|c|}{ Ranking } & \multicolumn{1}{|c|}{ Responsável } & \multicolumn{1}{c|}{ Critério } & \multicolumn{1}{c|}{ Regulamentação } \\
\hline $\begin{array}{l}\text { Desempenho Global de } \\
\text { Continuidade }\end{array}$ & $\begin{array}{l}\text { Superintendência de } \\
\text { Regulação dos serviços de } \\
\text { Distribuição (SRD) }\end{array}$ & Quantitativo & $\begin{array}{l}\text { Item 5.8.5, seção 8.2 do módulo 8 } \\
\text { dos Procedimentos de Distribuição - } \\
\text { PRODIST (ANEEL, 2017b, p. 63). }\end{array}$ \\
\hline $\begin{array}{l}\text { Limites de transgressão de } \\
\text { interrupção e Perdas } \\
\text { técnicas e não técnicas }\end{array}$ & $\begin{array}{l}\text { Superintendência de } \\
\text { Regulação dos serviços de } \\
\text { Distribuição (SRD) }\end{array}$ & Quantitativo & $\begin{array}{l}\text { Item 2.3, seção 7.4 do módulo 7 dos } \\
\text { Procedimentos de Distribuição - } \\
\text { PRODIST. (ANEEL, 2015c, 17) }\end{array}$ \\
\hline $\begin{array}{l}\text { Índice ANEEL de } \\
\text { Satisfação do Consumidor } \\
\text { (IASC) }\end{array}$ & $\begin{array}{l}\text { Superintendência de } \\
\text { Mediação Administrativa, } \\
\text { Ouvidoria Setorial e } \\
\text { Participação Pública (SMA) }\end{array}$ & Qualitativo & $\begin{array}{l}\text { Metodologia IASC (ANEEL, } \\
\text { 2016b). }\end{array}$ \\
\hline $\begin{array}{l}\text { Saúde financeira das } \\
\text { distribuidoras }\end{array}$ & $\begin{array}{l}\text { Superintendência de } \\
\text { Fiscalização Econômica e } \\
\text { Financeira (SFF) }\end{array}$ & Quantitativo & $\begin{array}{l}\text { Item RP 211.2 - Endividamento e } \\
\text { ativos Financeiros, do Manual de } \\
\text { Preenchimento do Relatório de } \\
\text { dnformações Trimestrais (ANEEL, } \\
\text { 2010, 10). }\end{array}$ \\
\hline
\end{tabular}

Fonte: (ANEEL, 2010; 2015d; 2016b; 2017b).

Com base nas características do problema de decisão, racionalidade dos decisores, critérios e alternativas identificadas, optou-se por utilizar um método da abordagem de sobreclassificação (escola francesa), o qual não permite compensação entre critérios. Para fins de obtenção do ranking foi utilizado o método Promethèe II, incorporado ao Visual Promethèe 1.4 proposto por Mareschal (2013). De acordo com Vincke (1992), métodos provenientes da abordagem de sobreclassificação fornecem soluções mais equilibradas, porque consideram a incomparabilidade de alternativas, bem como são capazes de incorporar a hesitação do decisor ao avaliar as alternativas mediante os critérios.

\subsection{Caracterização da Agência Nacional de Energia Elétrica (ANEEL)}

A ANEEL é uma autarquia em regime especial, vinculada ao Ministério de Minas e Energia (MME). Ela foi criada à época da desestatização do setor elétrico brasileiro, tendo iniciado suas atividades em dezembro/1997, a fim de regular o setor, por meio da Lei $n^{\circ} 9.427 / 1996$ e do Decreto $n^{\circ}$ 2.335/1997 (PRESIDÊNCIA DA REPÚBLICA, 1996; 1997).

À ANEEL compete a regulamentação, fiscalização, mediação, gestão tarifária, concessão (mediante delegação do MME) e implementação de políticas do governo federal relacionadas à energia elétrica (PRESIDÊNCIA DA REPÚBLICA, 1997). Para isso, a agência dispõe de 24 Unidades Organizacionais, a maioria delas são superintendências.

As superintendências de regulação do setor normatizam as políticas e diretrizes do Governo Federal, definem padrões de qualidade compatíveis com a realidade de cada região, com base nos impactos técnicos, econômicos e ambientais de suas ações. Existem três grupos de atuação, a regulação técnica de padrões de serviço, a regulação econômica e a dos projetos de pesquisa e desenvolvimento e eficiência energética.

As superintendências de fiscalização atuam nos serviços de geração, serviços de eletricidade e na fiscalização econômico-financeira, com o objetivo de garantir o atendimento aos padrões de qualidade estabelecidos pela regulação e pelos contratos assinados para operação do setor. A superintendência de gestão tarifária é responsável pelo estabelecimento das tarifas que viabilizam a estruturação do setor, desde a geração, passando pela transmissão, até a distribuição e comercialização da energia elétrica. A superintendência de mediação tem o objetivo de equilibrar os interesses do governo, setor privado e consumidores, responsável pela ouvidoria, processos de consultas e audiências públicas, entre outras atividades.

A ANEEL possui, ainda, unidades organizacionais responsáveis pela concessão de outorgas do serviço público de energia elétrica, que concedem ao setor privado a responsabilidade por produzir, transmitir e distribuir eletricidade no território nacional. Além dessas unidades, existem outras superintendências e órgãos de apoio, como a gestão da informação, licitações e contratos, administração financeira e orçamentária, auditoria interna e assessoria. 


\subsection{Critérios que basearam o modelo para classificação de concessionárias}

Os critérios de avaliação foram estabelecidos com base em duas premissas: i) a viabilidade e facilidade de obtenção das informações necessárias; e ii) a relevância para o estabelecimento do ranking desejado. No que se refere à relevância para o estabelecimento do ranking, o risco de perda de capacidade técnicooperacional pode ser avaliado com base em informações sobre a qualidade do fornecimento de energia elétrica de cada distribuidora. Já o risco de perda da capacidade econômico-financeira pode ser avaliado por meio de indicadores que definam diretamente a capacidade que tem a empresa de fazer frente aos seus compromissos financeiros.

Sendo as perdas não técnicas de energia um argumento também muito utilizado como justificativa para solicitação do alívio regulatório, foi considerado relevante para o estabelecimento do ranking. Por fim, uma informação exógena à empresa distribuidora, o Índice de Avaliação da Satisfação do Consumidor (IASC), foi também considerado relevante para a análise, por já ser utilizado para o ranking anual de satisfação do consumidor. As subseções seguintes descrevem detalhadamente cada critério utilizado na pesquisa. A fim de analisar os critérios existentes e utilizados pela Aneel, realizou-se uma análise documental. A próxima seção descreve em detalhes esses critérios.

\subsubsection{Qualidade do fornecimento de energia elétrica}

A qualidade percebida pelo consumidor de uma concessionária ou permissionária de serviço público de distribuição de energia elétrica é avaliada a partir de três grandes aspectos: a qualidade do "produto" energia elétrica (relacionada à conformidade da tensão em regime permanente e à ausência de perturbações na forma de onda), a qualidade do "serviço" (relacionada à continuidade na prestação do serviço) e a qualidade do atendimento ao consumidor (ANEEL, 2016b). Esses indicadores, são compilados por subestações (ou agrupamento de subestações) das distribuidoras, denominadas conjuntos elétricos. A ANEEL publica limites para indicadores associados a cada conjunto, definidos para períodos mensais, trimestrais e anuais. (ANEEL, 2017b).

A avaliação da continuidade na prestação do serviço compreende indicadores de interrupções no fornecimento de energia elétrica, destacando-se os indicadores de continuidade individuais (DIC, FIC), e os indicadores de continuidade coletivos (DEC e FEC) todos definidos no Módulo 8 dos Procedimentos de Distribuição - PRODIST (ANEEL, 2017b), e detalhados a seguir.

\section{- Duração de Interrupção Individual (DIC)}

Duração de interrupção individual por unidade consumidora ou por ponto de conexão, expressa em horas e centésimos de hora, calculada com a seguinte fórmula:

$$
D I C=\sum_{i=1}^{n} t(i)
$$

$t(i)=$ tempo de duração da interrupção da unidade consumidora considerada ou ponto de partida da conexão no período de apuração;

$n$ = número de interrupções da unidade consumidora considerada no período de apuração.

\section{- Frequência de Interrupção Individual (FIC)}

Frequência de interrupções por unidade consumidora ou por ponto de conexão, expresso em número de interrupções:

$$
F I C=n
$$

\section{- Duração Equivalente de Interrupção por Unidade Consumidora (DEC)}

Duração equivalente de interrupção por unidade consumidora, expressa em horas e centésimos de hora, utilizando a seguinte fórmula:

$$
D E C=\frac{\sum_{i=1}^{E D E} D e t ?}{C e}
$$

$i=$ índice de unidades consumidoras atendidas em BT ou MT faturadas do conjunto; 
$C c$ = número total de unidades consumidoras faturadas do conjunto no período de apuração, atendidas em BT ou MT.

\section{- Frequência Equivalente de Interrupção por Unidade Consumidora (FEC)}

Frequência equivalente de interrupção por unidade consumidora, expressa em número de interrupções e centésimos do número de interrupções:

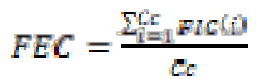

$i=$ índice de unidades consumidoras atendidas em BT ou MT faturadas do conjunto;

$C c=$ número total de unidades consumidoras faturadas do conjunto no período de apuração, atendidas em BT ou MT.

Ressalta-se que, similarmente a outros indicadores no mundo, esses indicadores são apurados para as interrupções maiores que 3 minutos, sendo admitidos alguns expurgos na sua apuração (ANEEL, 2017b).

\subsubsection{Desempenho Global de Continuidade (DGC)}

A Superintendência de Regulação dos Serviços de Distribuição (SRD) publica anualmente um ranking de distribuidoras com base no Desempenho Global de Continuidade, que visa avaliar o nível da continuidade (valores apurados de duração e frequência de interrupções) em relação aos limites estabelecidos para a sua área de concessão - limites determinados pelas resoluções autorizativas da ANEEL (ANEEL, 2017a: 2).

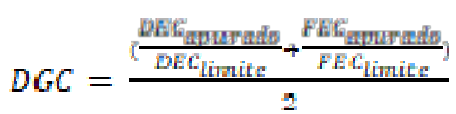

$D E C_{\text {apurado }}=$ Duração Equivalente de Interrupção por Unidade Consumidora (valor apurado anual);

$D E C_{\text {lizmite }}=$ Duração Equivalente de Interrupção por Unidade Consumidora (valor limite anual);

$F E C_{\text {avarado }}=$ Frequência Equivalente de Interrupção por Unidade Consumidora (valor apurado anual);

$F E C_{\text {limite }}=$ Frequência Equivalente de Interrupção por Unidade Consumidora (valor limite anual).

\section{- DEC e FEC relativos $\left(D_{R} C_{R}\right.$ e FEC $\left.R\right)$}

É imediato verificar que o DGC, tal como definido, é um critério compensatório, já que empresas com poucas interrupções de longa duração podem ter o índice equivalente a empresas com muitas interrupções de pouca duração. Para evitar esse efeito, serão considerados individualmente na análise os critérios DEC e FEC relativos $\left(\mathrm{DEC}_{\mathrm{R}}\right.$ e $\left.\mathrm{FEC}_{\mathrm{R}}\right)$, conforme definidos:

$$
D E C_{\mathbb{R}}=\frac{D E C_{\text {apurado }}}{D E C_{\text {limite }}} \quad F E C_{R}=\frac{F E C_{\text {mpurvalf }}}{\text { FEC }}
$$

(Fórmula 7)

\subsubsection{Indicadores de sustentabilidade econômico-financeira}

A Superintendência de Fiscalização Econômica e Financeira - SFF é responsável pelo Relatório de Indicadores de Sustentabilidade Econômico Financeira das Distribuidoras, no qual constam 5 indicadores que são monitorados ao longo do tempo para verificar se a situação atual é transitória ou estrutural (ANEEL, 2014a). Neste artigo foram utilizados os dois principais indicadores desse relatório, endividamento e eficiência.

O LAJIDA (Lucro Antes dos Juros, Impostos, Depreciação e Amortização), ou EBITDA (Earnings Before Interests, Taxes, Depreciation and Amortization), é a geração de caixa operacional bruta, ou lucro operacional do negócio. O endividamento é definido como uma proporção da dívida líquida da empresa em relação ao seu Fluxo da Atividade (considerando os investimentos são definidos pelo Regulador como QRR, não os reais). 


$$
\text { Endividamento }=\frac{\text { Divida Liquida }}{\text { EBIDTA-ORA }}
$$

A eficiência corresponde à proporção do Custo Operacional Ajustado em relação ao Custo Operacional definido pelo Regulador, dos Últimos Doze Meses - UDM.

$$
\text { Eficiência }=\frac{\text { PMSO Ajustado PDM }}{\text { PMSO Regulatório }}
$$

\subsubsection{Perdas não técnicas}

As perdas na distribuição correspondem a diferença entre a energia injetada na rede e o total de energia vendida e entregue, e é composta pelas perdas técnicas e não técnicas. As perdas técnicas são a parcela inerente ao processo de transporte, transformação de tensão e medição da energia na rede. As perdas não técnicas correspondem as demais perdas associadas à distribuição de energia elétrica, como por exemplo furtos de energia, erros de medição, erros no processo de faturamento, unidades consumidoras sem equipamento de medição. Representam a diferença entre as perdas na distribuição e as perdas técnicas.

\section{- Percentual de Perdas Técnicas - PPT:}

Percentual de perdas técnicas em relação à energia injetada.

$$
P P T=\frac{P T}{E I} \times 100
$$

(Fórmula 10)

$P T=$ energia dissipada no sistema de distribuição devido a fenômenos da física (MWh);

$E I=$ energia proveniente de agentes supridores e da geração própria para atendimento ao mercado da distribuidora (MWh).

- Percentual de Perdas na Distribuição - PPD:

Percentual de perdas totais em relação à energia injetada.

$$
P P D=\left(1-\frac{E F}{E I}\right) \times 100
$$

$E F=$ energia fornecida às unidades consumidoras cativas e livres, mais o consumo próprio (MWh); $E I=$ energia proveniente de agentes supridores e da geração própria para atendimento ao mercado da distribuidora (MWh).

\section{- Percentual de Perdas Não Técnicas - PPNT}

Diferença entre o percentual de perdas na distribuição e o percentual de perdas técnicas.

$$
P P N T=P P D-P P T
$$

A ANEEL classifica as empresas em grupos, de acordo com o percentual de perdas não técnicas, e define uma trajetória para a redução desse percentual, com metas anuais ou a serem atingidas no ano da respectiva revisão tarifária (ANEEL, 2016a).

\subsection{5 Índice de Avaliação da Satisfação do Consumidor - IASC}

O IASC é um indicador que avalia a satisfação do consumidor residencial com os serviços prestados pelas distribuidoras de energia elétrica (ANEEL, 2016c). O critério IASC é obtido anualmente a partir de pesquisa amostral realizada com consumidores de todas as distribuidoras, concessionárias e permissionárias, que atuam no território nacional. $O$ Índice é composto por cinco variáveis em questionário no qual as respostas estão em escala de mensuração (ANEEL, 2015b). São cinco os critérios avaliados: i) qualidade percebida; ii) valor percebido (relação custo-benefício); iii) satisfação global; iv) confiança no fornecedor; e v) fidelidade.

No método Promethèe podem ser escolhidos diversos tipos de critérios a fim de viabilizar a análise de dados, conforme Almeida e Costa (2003). Nesse estudo convencionou-se utilizar o critério gaussiano, considerando que a preferência por determinada alternativa aumenta segundo uma distribuição normal, cabe destacar que esse tipo de critério é o mais comumente utilizado em aplicações do método Promethèe, 
considerando que grande parte dos dados podem ser representados por uma distribuição normal.

Adicionalmente, é importante destacar que os dados foram normalizados a fim de evitar que a representação no Plano Gaia ficasse enviesada para as variáveis com maior ordem de grandeza. Assim sendo, a normalização foi realizada para que todos os critérios analisados fossem visualizados considerando a mesma ordem de grandeza. Considerando que a distribuição da performance das alternativas mediante os critérios qualitativos e quantitativos, descritos na seção 3.1, seguiam uma distribuição normal, considera-se essa prática aceitável. O Plano Gaia é a ferramenta visual do método Promethèe que facilita a visualização dos dados gerados e possibilita uma análise detalhada dos resultados obtidos, facilitando consequentemente, a tomada de decisões.

\section{Apresentação e discussão dos resultados}

\subsection{Descrição do problema de decisão e modelo proposto}

Do ponto de vista metodológico, o problema é típico para o uso de uma abordagem AMD, por envolver múltiplos critérios e várias alternativas. Ademais, tendo em vista a necessidade de ordenar as distribuidoras segundo critérios definidos, verifica-se a problemática de ordenação. Durante as entrevistas realizadas com os decisores, foi verificado que a compensação entre critérios poderia mascarar o desempenho das concessionárias e dificultar a sua segregação. Portanto, foi escolhida a racionalidade não aditiva, a qual fornece soluções mais equilibradas, tendo em vista que todas os critérios deverão apresentar um desempenho satisfatório a fim de se obter a solução mais adequada, adequando-se à abordagem de sobreclassificação. Assim, evitam-se que determinadas soluções sejam escolhidas devido a um excelente desempenho em dado critério em detrimento de um péssimo desempenho em outro.

Dessa forma, optou-se pela utilização do método Promethèe, com base no software versão acadêmica, Visual Promethèe 1.4 Academic Edition, em http://www.promethee-gaia.net.

O presente trabalho aborda a detecção de empresas distribuidoras de energia elétrica cuja situação econômico-financeira e a qualidade do serviço estejam de tal forma degradadas que o cumprimento das regras vigentes de ressarcimento aos consumidores as impossibilitem de realizar investimentos na melhoria da própria rede de distribuição.

Nesse contexto, cabe à Diretoria colegiada da ANEEL autorizar medidas de alívio regulatório. Caso ela chegue a essa decisão, é formalizado um Termo de Ajuste de Conduta - TAC, com a empresa distribuidora de energia. O TAC pode isentar a regulada de ressarcimentos às unidades consumidoras pela transgressão dos indicadores individuais de continuidade e de tensão, e reverter esse valor em investimentos na melhoria da rede de distribuição. Esse investimento deverá ser contabilizado, parte como investimento remunerado (repassado à tarifa de energia), parte como obrigações especiais (não remunerada pela tarifa). No TAC são fixadas as metas anuais dos indicadores de qualidade que a empresa deve atingir, e os percentuais correspondentes de redução nos valores de compensação. Caso a regulada não atinja as metas anuais, fica obrigada a investir em dobro o valor que seria ressarcido aos consumidores, sendo todo esse montante contabilizado como obrigações especiais. Assim, fica mantido o incentivo ao investimento na qualidade do serviço prestado.

Para evitar a degradação da qualidade do fornecimento de energia elétrica, é necessário identificar as empresas nas quais a qualidade do fornecimento começa a trajetória de decadência, para este fim o método AMD mostra-se adequado

O ordenamento das empresas de distribuição energia, levando em conta as suas diferentes características, permitirá a adoção, por parte do órgão regulador, de medidas diferenciadas para as que tiverem maior risco. Atualmente, o setor de distribuição de energia elétrica é composto por 63 Concessionárias, 38 Permissionárias e 13 Autorizadas, totalizando 114 agentes, entre públicos, privados e de economia mista, atuando no mercado de distribuição (ANEEL 2015). A Agência dispõe de uma grande quantidade de indicadores de desempenho das empresas. Entretanto, para este trabalho, a quantidade de agentes e critérios foi reduzida de forma a simplificar e permitir o uso da versão acadêmica da ferramenta Visual Promethèe 1.4.

A estruturação do modelo é necessária para que sejam definidos os dados e parâmetros de entrada no 
software escolhido. A Figura 5 apresenta a proposta de modelo para ordenação das concessionárias e gestão destas, a fim de reduzir o risco de interrupções. O modelo engloba a modelagem multicritério com etapas prédefinidas, conforme a Figura 1.

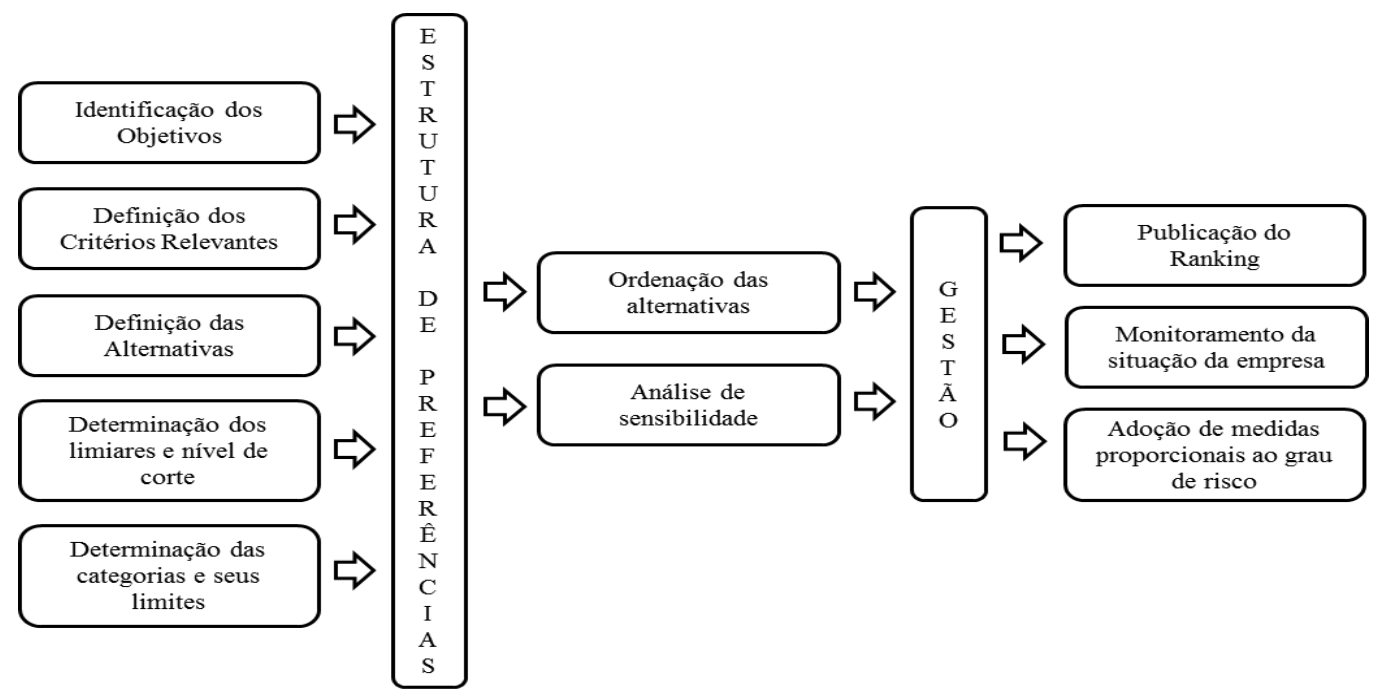

Figura 1 - Modelo proposto para gestão do desempenho das concessionárias de distribuição.

A decisão sobre o alívio regulatório cabe à Diretoria Colegiada da ANEEL, que se baseia em Notas Técnicas das Superintendências responsáveis pela regulação e fiscalização do setor. No âmbito desse trabalho, foram consultadas as superintendências de Regulação da Distribuição (SRD), de Gestão Tarifária (SGT), de Fiscalização Econômico-Financeira (SFF) e de Mediação Administrativa, Ouvidoria Setorial e Participação Pública (SMA).

Com base nas entrevistas foi possível identificar que o objetivo de decisão é ordenar as concessionárias, em ordem decrescente, da melhor para a pior de forma a identificar quais empresas apresentam maior risco de perda de capacidade operacional e tomar medidas para mitigar esse risco. $\mathrm{O}$ método Promethèe, conforme Mohammadi e Rezaei (2020) permite calcular o fluxo positivo outr + (que sobreclassificam uma alternativa), e negativo outr - (cuja alternativa é sobreclassificada por outra), resultando no fluxo líquido para cada alternativa, mediante os critérios selecionados. O resultado do fluxo líquido é ordenado em ordem decrescente, demonstrando que as alternativas com maior índice que sobreclassificam mais (dominam) são apresentadas no topo do ranking, enquanto as que são mais sobreclassifcadas ficam nas posições inferiores do ranking. Nesse problema específico, as que ficam no topo do ranking são as que possuem mais riscos e devem ser priorizadas pelos decisores, a fim de que o controle seja mais efetivo e frequente.

Com base nos critérios apresentados na seção 3.2, foi determinado um conjunto de critérios para o modelo proposto, os quais são apresentados no Quadro 3. Os critérios de decisão foram baseados nas justificativas das concessionárias ao pleitearem o alívio regulatório, como a degradação da qualidade do fornecimento, o aumento das perdas não técnicas, alto nível de ressarcimento aos consumidores (diretamente relacionado ao baixo nível de serviço), altos índices de dívida líquida e inadimplência tributária e setorial, não recebimento (atraso no recebimento) de mútuos ativos.

Quadro 3. Determinação dos critérios de decisão.

\begin{tabular}{|l|l|l|}
\hline GRUPO & CRITÉRIOS & TIPO \\
\hline Fatores técnico-operacionais & Indicadores de qualidade DECR e FEC $R$ & Minimização \\
\hline \multirow{2}{*}{ Fatores econômico-financeiros } & Endividamento & Minimização \\
\cline { 2 - 3 } & Eficiência operacional & Maximização \\
\hline Fatores sociais & Perdas não técnicas & Minimização \\
\hline Satisfação dos consumidores & IASC & Maximização \\
\hline
\end{tabular}

O grupo de fatores técnico-operacionais engloba os indicadores de qualidade da energia elétrica. O tipo ser de maximização significa que ambos indicadores são melhores quanto maiores os valores informados. $\mathrm{O}$ de fatores financeiros está relacionado ao desempenho da empresa no pagamento quanto ao seu 
endividamento e sua eficiência relativa à definida pelo regulador. Quanto menor o nível endividamento. Para a eficiência, quanto maior, melhor. O índice de perdas não técnicas é utilizado como proxy para o indicador social, visto que há correlação entre o furto de energia e a situação social de uma área de concessão. Ele é melhor quanto menor o valor informado. O IASC é utilizado como indicador de satisfação dos consumidores. Quanto maior o IASC, melhor a satisfação.

Portanto, foi realizada uma consulta a todos os processos de tratamento de pedidos de socorro feitos pelas distribuidoras de energia elétrica à ANEEL, as quais enfrentaram alguma dificuldade técnicooperacional e financeira, autuadas nos respectivos processos de termo de ajuste de conduta. Com bases nos motivos informados nos documentos existentes, os quais teriam levado as empresas a uma degradação financeira ou operacional, foram definidos os critérios que seriam analisados nesse estudo. Assim sendo, destaca-se que não foram realizadas entrevistas ou consultas diretamente às distribuidoras, tendo em vista que o foco é a análise de decisão da agência reguladora quanto ao risco de não distribuição de energia elétrica aos consumidores finais.

Em função da disponibilidade de informações, o foco do trabalho restringiu-se às concessionárias, denominadas alternativas no âmbito da análise multicritério. A partir do universo de 62 concessionárias, para fins deste trabalho, foi utilizada uma amostra com 10 alternativas. A escolha de uma quantidade pequena de alternativas se deve à limitação da ferramenta PROMETHEE, na versão acadêmica.

Cabe ressaltar que, ao criar dispositivos regulatórios, a Aneel realiza processos de participação pública (audiências, consultas públicas e solicitações de contribuições), com rito e prazos próprios. Realizar entrevistas informais com as empresas distribuidoras ou realizar um processo de participação pública, seria inviável, devido ao tempo que esses processos tomam. Portanto, considerando o propósito de demonstrar a aplicabilidade da AMD na classificação de empresas do setor elétrico, não cabia a realização de um processo de participação pública formal, sendo a consulta aos processos históricos uma confiável fonte de dados.

A racionalidade do processo decisório foi identificada por meio de entrevistas com colaboradores das Superintendências que subsidiam as decisões da Diretoria Colegiada da Aneel. Cada colaborador, considerado decisor, definiu os limiares de preferência e indiferença apenas sobre as informações pelas quais se responsabiliza, sem opinar sobre os demais critérios. Os pesos de cada alternativa foram definidos pelos responsáveis pela aplicação do método multicritério, que são também servidores da Aneel e atuam diretamente na análise dos rankings das concessionárias, após consenso sobre o grau de relevância que cada critério deveria ter na avaliação.

A escolha das alternativas ocorreu a partir do ranking do Desempenho Global da Continuidade de 2016. $\mathrm{O}$ documento estabelece, na realidade, dois rankings, um para empresas de grande porte (com mais de 400.000 consumidores) e outro para as de pequeno porte (com até 400.000 consumidores). Foram consideradas para a amostra 5 empresas de grande porte e 5 de pequeno porte, segundo a classificação da ANEEL. Para compor cada um desses conjuntos de empresas, foram escolhidas em cada ranking uma empresa com bom desempenho e quatro dentre as com pior desempenho, tendo em conta a disponibilidade dos indicadores para elas. A amostra escolhida foi composta pelas seguintes empresas: Companhia Energética do Maranhão - CEMAR; Companhia Energética do Ceará - COELCE; Eletrobrás Distribuição Rondônia S.A. CERON; Empresa Luz e Força Santa Maria - ELFSM; Energisa Paraíba Distribuidora de Energia S.A. EPB; Energisa Borborema Distribuidora de Energia S.A. - EBO; Elektro Distribuidora de Energia ELEKTRO; Companhia Força e Luz do Oeste - CFLO; Muxfeldt, Marin \& Cia Ltda. - MUXENERGIA; Energia Campolarguense - COCEL.

Com base nas entrevistas com os decisores também foi possível obter os limiares dos critérios. O resultado das entrevistas com os especialistas está no Quadro 5.

Quadro 5. Determinação dos limiares e pesos dos critérios

\begin{tabular}{|l|l|l|l|l|l|}
\hline Critério & Peso & $\begin{array}{l}\text { Limite de } \\
\text { indiferença }\end{array}$ & $\begin{array}{l}\text { Limite de } \\
\text { indiferença } \\
\text { normalizado }\end{array}$ & $\begin{array}{l}\text { Limite de } \\
\text { preferência }\end{array}$ & $\begin{array}{l}\text { Limite de } \\
\text { preferência } \\
\text { normalizado }\end{array}$ \\
\hline Endividamento & 3 & 1 & 0,0100 & 7 & 0,0700 \\
\hline Eficiência Operacional & 2 & 10 & 0,1000 & 50 & 0,5000 \\
\hline Perdas Não Técnicas & 1 & 14 & 0,1141 & 46 & 0,3749 \\
\hline
\end{tabular}




\begin{tabular}{|l|l|l|l|l|l|}
\hline IASC & 1 & 8 & 0,2981 & 36 & 1,3413 \\
\hline $\mathrm{DEC}_{\mathrm{R}}$ & 3 & N/A & N/A & N/A & N/A \\
\hline FEC $_{\mathrm{R}}$ & 3 & N/A & N/A & N/A & N/A \\
\hline
\end{tabular}

No caso do $\mathrm{DEC}_{\mathrm{R}}$ e $\mathrm{FEC}_{\mathrm{R}}$, o decisor informou que não havia limiares de indiferença ou preferência. Para eles, foi então considerada uma distribuição gaussiana.

\subsection{Aplicação do Modelo}

Com base em ampla análise documental, os dados para a amostra foram obtidos das seguintes fontes: i) Endividamento e Eficiência: Relatório de Informações Trimestrais de dezembro de 2016, sem publicação, ANEEL/ SFF; Perdas não Técnicas, sem publicação: ANEEL/SRD; IASC: Relatório Pesquisa IASC 2016. Brasil, Categorias e Distribuidoras (ANEEL 2016c); $\mathrm{DEC}_{\mathrm{R}}$ e $\mathrm{FEC}_{\mathrm{R}}$ : Nota Técnica no 023/2017-SRD/ANEEL. Indicador de Desempenho Global de Continuidade de 2016 (ANEEL, 2017a). Ressalta-se que os dados foram normalizados, de acordo com a fórmula:

$$
n_{\bar{i}}=\frac{\left.x_{i}-\min (x)\right)}{\max (x)-\min (x)}
$$

$x_{i}=$ valor original do critério para a alternativa $i ; n_{i}=$ valor do critério normalizado para a alternativa i.; $\max (x)=$ maior valor para o critério; $\min (x)=$ menor valor para o critério.

Quadro 6. Dados para os critérios da amostra normalizados

\begin{tabular}{|l|c|c|r|r|r|r|}
\hline \multicolumn{1}{|c|}{ Empresa } & $\begin{array}{c}\text { Endivida- } \\
\text { mento }\end{array}$ & $\begin{array}{c}\text { Eficiência- } \\
\text { PMSO }\end{array}$ & $\begin{array}{c}\text { Perdas Não } \\
\text { Técnicas }\end{array}$ & IASC & DEC $_{\mathbf{R}}$ & FEC $_{\mathbf{R}}$ \\
\hline CEMAR & 0,0220 & 0,2298 & 0,1425 & 0,1479 & 0,3302 & 0,2989 \\
\hline COELCE & 0,0200 & 0,2592 & 0,2884 & 0,3141 & 0,3491 & 0,3103 \\
\hline CERON & 1,0000 & 1,0000 & 1,0000 & 0,1237 & 1,0000 & 1,0000 \\
\hline ELFSM & 0,0000 & 0,0000 & 0,3394 & 0,5559 & 0,1981 & 0,2184 \\
\hline EPB & 0,0260 & 0,1491 & 0,1513 & 0,7194 & 0,4623 & 0,2874 \\
\hline EBO & 0,0090 & 0,2046 & 0,0000 & 0,7921 & 0,0000 & 0,0000 \\
\hline ELEKTRO & 0,0410 & 0,1842 & 0,3410 & 0,4654 & 0,5472 & 0,3793 \\
\hline CFLO & 0,4340 & 0,0570 & 0,2396 & 0,7716 & 0,2358 & 0,1724 \\
\hline MUXENERGIA & 0,0000 & 0,1997 & 0,2429 & 1,0000 & 0,2358 & 0,2299 \\
\hline COCEL & 0,0000 & 0,3284 & 0,3322 & 0,0000 & 0,6604 & 0,9195 \\
\hline
\end{tabular}

Com este tipo de normalização se uniformiza o menor e o maior valor dos dados para o critério em 0 e 1, respectivamente. A escolha das funções de preferência foi baseada nas entrevistas junto aos decisores, pois dependia da determinação dos limiares de indiferença e preferência. Como na maioria dos critérios esses limiares foram encontrados, utilizou-se a função linear. No caso dos indicadores de qualidade, utilizou-se a função gaussiana, pois não foram determinados os limiares. De acordo com os parâmetros fornecidos, conforme a Figura 2, a EBO é a empresa com melhor desempenho geral e a CERON a com pior desempenho considerando o fluxo $\Phi$ líquido (\$+- $\left.\Phi_{-}\right)$.

\begin{tabular}{|c|c|c|c|c|c|}
\hline \multicolumn{4}{|c|}{ 圈 PROMETHEE Flow Table } & \multirow{2}{*}{ Phit } & \multirow{2}{*}{$\begin{array}{l}\times \\
\text { Phi- }\end{array}$} \\
\hline Rank & & & Phi & & \\
\hline 1 & EBO & $\square$ & 0,5724 & 0,5905 & 0,0181 \\
\hline 2 & MUXENERGIA & $\square$ & 0,2315 & 0,3171 & 0,0855 \\
\hline 3 & ELFSM & $\square$ & 0,2013 & 0,3252 & 0,1239 \\
\hline 4 & CEMAR & $\square$ & 0,0393 & 0,2087 & 0,1694 \\
\hline 5 & COELCE & $\square$ & 0,0191 & 0,1960 & 0,1768 \\
\hline 6 & CFLO & $\square$ & $-0,0083$ & 0,2932 & 0,3015 \\
\hline 7 & EPB & $\square$ & $-0,0334$ & 0,1745 & 0,2080 \\
\hline 8 & ELEKTRO & $\square$ & $-0,1841$ & 0,1348 & 0,3188 \\
\hline 9 & COCEL & $\square$ & $-0,2688$ & 0,1290 & 0,3978 \\
\hline 10 & CERON & $\square$ & $-0,5690$ & 0,1538 & 0,7229 \\
\hline
\end{tabular}

Figura 2 - Ranking proposto para gestão do desempenho das concessionárias de distribuição.

Outra forma de visualizar o ordenamento é o gráfico do ranking completo. Nele é possível visualizar de maneira mais intuitiva a distância entre os desempenhos das empresas, conforme a Figura 3. 


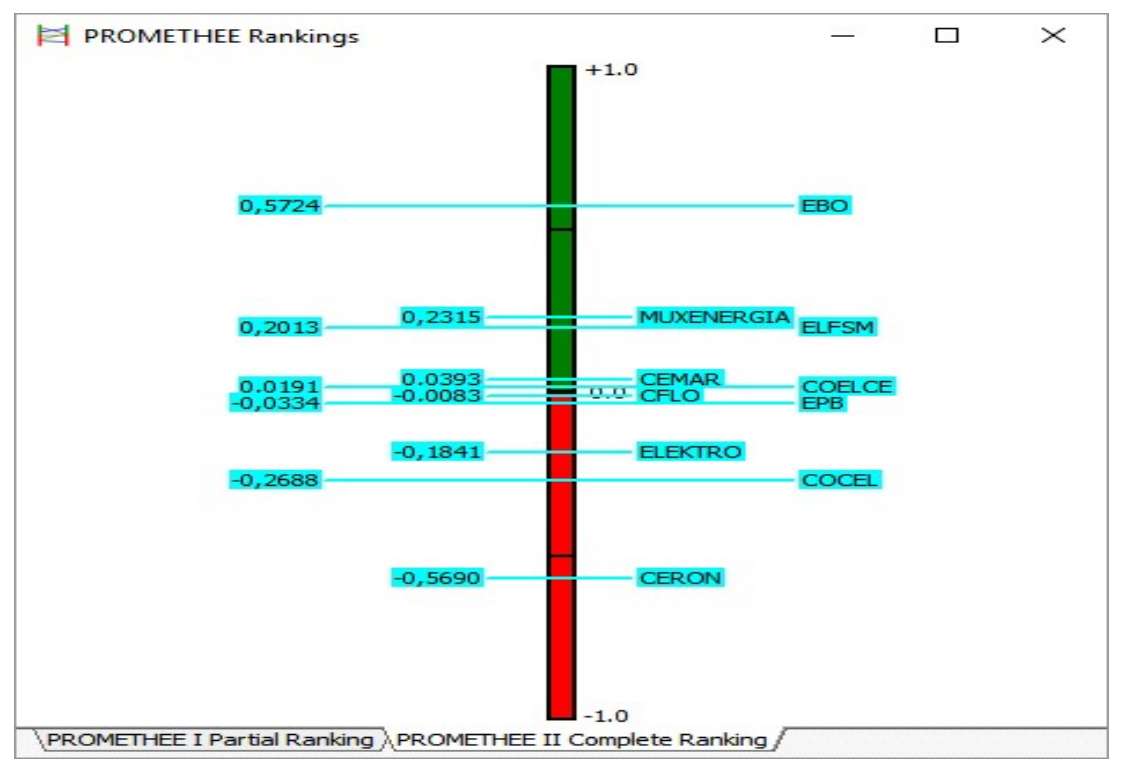

Figura 3 - Ranking completo

Na Figura 3, verifica-se que o desempenho da EBO se destaca dos demais que possuem fluxo positivo. As empresas ELFSM e MUXENERGIA estão muito próximas. Um pouco abaixo, COELCE, CEMAR, COELCE, COCEL CFLO e EPB também possuem desempenho semelhante. Destacam-se negativamente a ELEKTRO, COCEL e CERON, com desempenho bastante diferente do das demais concessionárias. Outra forma de visualizar o resultado é o Plano Gaia, conforme Figura 4. Esta visualização utiliza um método matemático chamado Principal Components Analysis para reduzir o número de dimensões (cada um dos seis critérios é uma dimensão) a duas, minimizando a perda de informação.

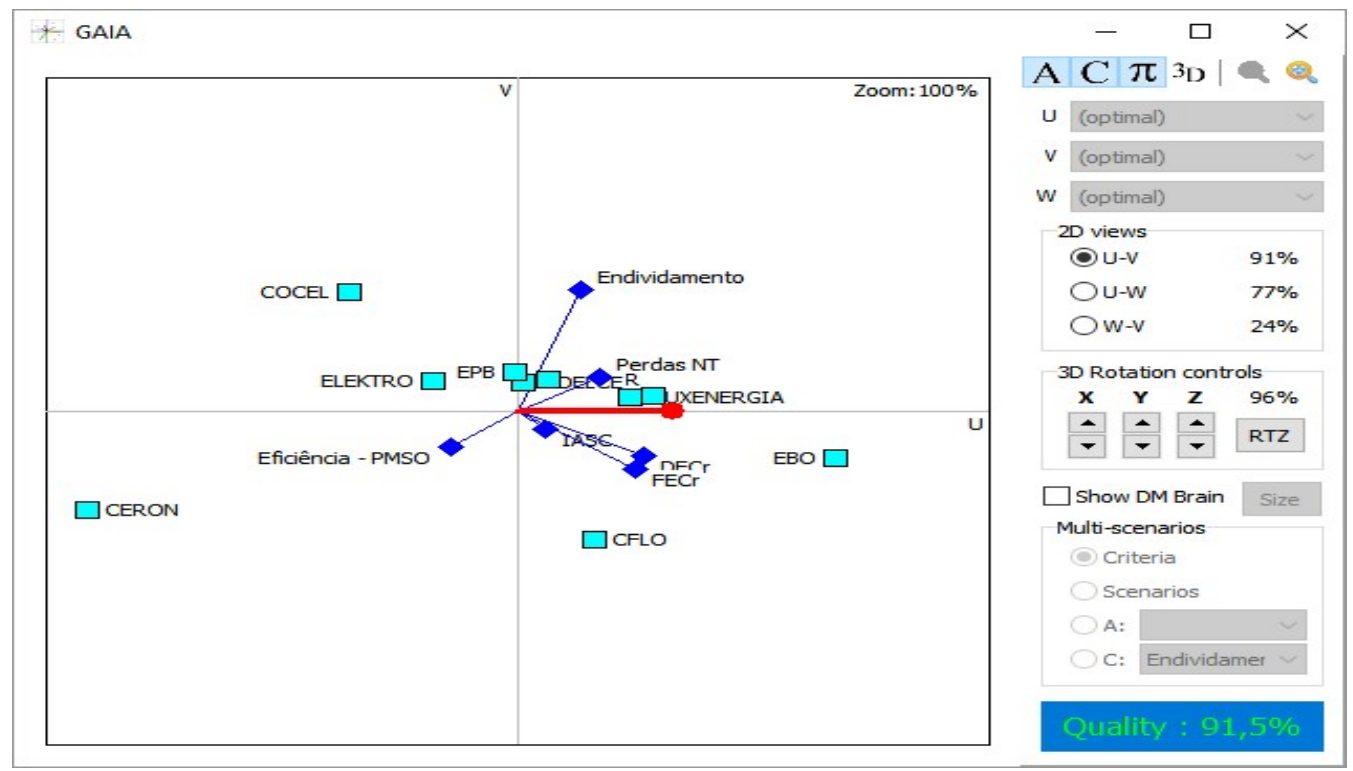

Figura 4 - Plano Gaia.

A visualização fornecida pelo gráfico acima perde apenas 8,5\% da informação (qualidade 91,5\%), equivalente ao plano UV, que provê a maior quantidade de informação possível num plano de duas dimensões. As alternativas (empresas) são exibidas como pontos (quadrados). Os critérios são representados como eixos na cor azul. O peso dos critérios e o ranking são representados pelo eixo de decisão (vermelho). A posição das empresas está relacionada às suas avaliações no conjunto de critérios de forma que as que possuírem perfis semelhantes vão estar próximas umas das outras.

A orientação dos eixos dos critérios indica quão relacionados um ao outro eles estão. No caso em estudo, o IASC mostrou forte relação com DEC e FEC, o que é de certa forma intuitivo, já que a satisfação 
dos usuários tende a aumentar à medida que a qualidade do serviço sobe. Eixos em orientações opostas indicariam critérios conflitantes, o que ocorreu no caso das Perdas Não Técnicas e Eficiência.

A Figura 5 permite visualizar ainda o desempenho das empresas em cada critério. Isso é feito considerando a projeção das alternativas sobre o eixo do critério, (distância do centro até o ponto em que as linhas pontilhadas tocam o eixo), não pela simples distância.

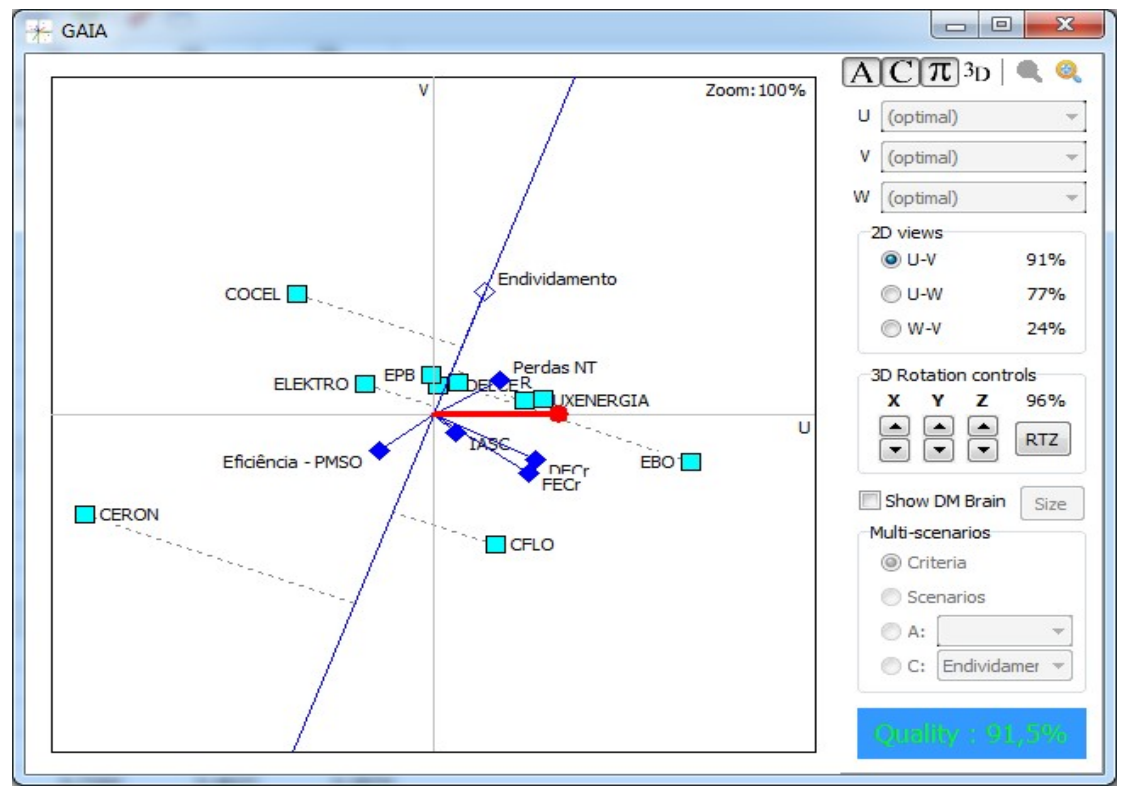

Figura 5 - Plano Gaia - Eixo Endividamento.

Por exemplo, considerando o eixo do Endividamento, as empresas COCEL, ELEKTRO, CFLO e CERON possuem projeções distantes umas das outras. As demais empresas possuem um desempenho próximo nesse critério. Análises dos rankings individuais com certeza atendem às necessidades de públicos específicos. Por exemplo, há interesse dos acionistas de uma concessionária pelo desempenho econômico e financeiro dela. A população em geral pode estar mais preocupada com o desempenho operacional.

É intuitivo concluir que, se o ranking AMD é estabelecido segundo uma ponderação dos valores informados para os critérios individuais, a posição de determinada alternativa no ranking AMD deverá estar entre a posição mínima e a máxima ocupada pela mesma alternativa nos rankings individuais. Essa comparação pode ser utilizada como evidência da robustez dos critérios de avaliação utilizados.

Para o caso em estudo, a Figura 6 representa a diferença da situação de cada distribuidora na análise AMD (primeira coluna) e nos demais rankings. Observa-se que a posição de cada empresa no ranking AMD é intermediária em relação à situação dela nos demais rankings, sendo mais determinantes para a posição AMD os critérios com maior peso.

Assim, por exemplo, a ELFSM ocupa o terceiro lugar no ranking AMD, sendo também a distribuidora com melhor situação no ranking de endividamento ( $1^{\circ}$ lugar), a pior em eficiência ( $10^{\circ}$ lugar), estar entre as piores quanto às perdas não técnicas ( $8^{\circ}$ lugar), na média quanto ao IASC ( $5^{\circ}$ lugar), e ter boa colocação na qualidade do fornecimento de energia ( $2^{\circ}$ lugar em $\mathrm{DEC}_{\mathrm{R}}$ e $3^{\circ}$ lugar em $\mathrm{FEC}_{\mathrm{R}}$ ). Nota-se também que tiveram maior peso na avaliação os critérios de endividamento e de qualidade. O mesmo comportamento se observa em relação às outras concessionárias de distribuição.

A principal conclusão a partir do gráfico é a de que a análise das distribuidoras com base unicamente nos rankings individuais pode conduzir à tomada de decisões equivocadas, já que não são considerados os pesos e limiares, nem o relacionamento entre critérios. A AMD consegue agregar efetivamente os vários critérios em um único ranking ponderado, e que seja útil ao processo de decisão. 


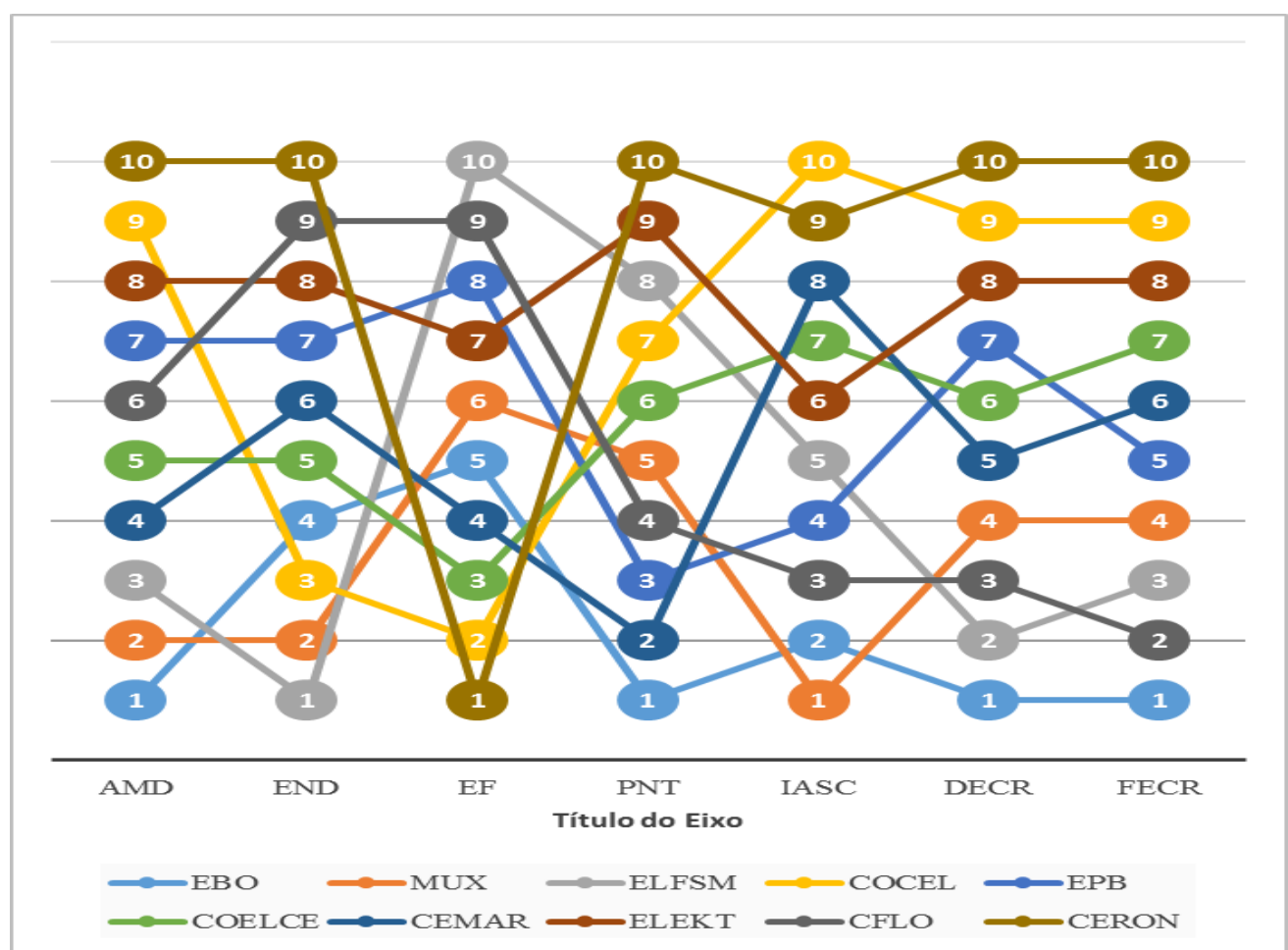

Figura 6 - Comparação entre a posição das concessionárias de distribuição no ranking multicritério e nos rankings individuais.

Por fim, não se pode deixar de mencionar os riscos inerentes ao processo de trabalho, que podem gerar imprecisões no ranking AMD. Eles são de três ordens: riscos relacionados à coleta de informações; riscos relacionados a imprecisões nos parâmetros do ranking; e riscos relacionados ao processo decisório.

Os riscos relacionados à coleta de informações se originam das fontes que as fornecem. As informações econômico-financeiras das distribuidoras se originam delas próprias, e podem conter inverdades, imprecisões e omissões. Idem para as informações sobre a qualidade no fornecimento de energia elétrica, consolidadas nos conjuntos elétricos a partir das informações do consumo individual. A fiscalização realizada pela ANEEL sobre a qualidade do fornecimento ocorre por amostragem, e é, portanto, ampla a chance de que os conjuntos não fiscalizados contenham informações imprecisas. Por fim, o IASC, apesar da forte correlação com os indicadores de qualidade, pode trazer subjetividade ao processo, já que o índice é tabulado a partir de informações prestadas pelos consumidores.

Os riscos relacionados à imprecisão nos parâmetros de levantamento se originam a partir da qualidade das respostas dos decisores. Observa-se, por exemplo, que o limiar de preferência normalizado para o IASC ficou acima de 1 . Isso se deve ao fato de o limiar de preferência original (36) ter sido estimado em função do ranking completo das distribuidoras, ultrapassando a diferença entre os valores máximo e mínimo da amostra. Essas imprecisões podem ser mitigadas com o aumento da quantidade de entrevistados, pois em função de diferentes opiniões podem ser obtidos parâmetros mais precisos, por exemplo a média do valor fornecido por vários dos decisores.

Os riscos relacionados ao processo decisório dizem respeito à desconsideração da análise multicritério, por motivos vários, inclusive os de viés político, em decisões de alívio econômico-financeiro exaradas pela ANEEL. A mitigação desse risco está no fato de ter o ranking AMD potencial para identificar as empresas que começam a trajetória de degradação econômico-financeira, permitindo medidas preventivas antes que a situação se agrave, minimizando, portanto, a quantidade de deliberações desse tipo.

\subsection{Discussão de Resultados}

Cabe observar que o ranking AMD possui afinidade com os rankings formais publicados pela ANEEL no ano de 2017. A Nota Técnica $n^{\circ}$ 023/2017-SRD/ANEEL, que descreve o ranking de fatores técnicooperacionais - Desempenho Global de Continuidade, corrobora o resultado do ranking AMD obtido nesse estudo. 
Quando se associa o ranking AMD ao ranking do fator satisfação do consumidor, IASC, a similaridade diminui. No entanto, ainda permanece na mesma direção, conforme mostra a Figura 4. Esse fato ocorre como resultado da subjetividade do conceito "satisfação" que o índice engloba.

Similarmente a Fittipaldi et al. (2000), que observou que a abordagem de Apoio Multicritério à Decisão é uma ferramenta de auxílio à tomada de decisão envolvendo a comercialização de energia elétrica no setor brasileiro, e recomendou que a metodologia fosse utilizada na determinação dos melhores portfolios de aplicações e investimentos no setor, o presente estudo demonstrou que pode ser também aplicada na determinação das melhores empresas do setor elétrico. Essa aplicação pode ser realizada considerando critérios diversos, técnicos e financeiros, permitindo ainda, o monitoramento e a tomada de decisões tempestivas para evitar a degradação dos serviços prestados aos cidadãos.

Neste trabalho, foi demonstrada a viabilidade de uso da AMD no processo decisório de elaboração de Termos de Ajuste de Conduta de empresas do setor elétrico brasileiro, corroborando o estudo de Zannuzzi et al. (2009), que expressou a vantagem do uso do método PROMETHEE II nos processos decisórios típicos dos gestores públicos. Estes autores salientaram que a metodologia é de fácil entendimento, potencializando a transparência do processo decisório, aspecto necessário na gestão pública.

Entretanto, é possível salientar a contribuição específica do presente estudo, na utilização da AMD para monitoramento e prevenção de situações que levem a processos de ajuste de conduta. Adicionalmente, Schmitz et al. (2016) utilizaram a AMD para criar uma lista de localidades a serem priorizadas no processo decisório de destinação de investimentos e políticas públicas para garantia de segurança e qualidade do suprimento energético no estado do Rio Grande do Sul, o que vai ao encontro dos resultados encontrados neste estudo, demonstrando a importância do uso de ferramentas que sistematizem as decisões relacionadas à continuidade do suprimento energético.

Considera-se, ainda, que o presente trabalho é complementar ao de Lopez e de Almeida (2014), que desenvolveu um modelo para seleção de projetos oriundos do planejamento estratégico de uma empresa do setor elétrico brasileiro, na medida em que poderiam ser priorizados os projetos que possuíssem maior potencial de elevar o desempenho da empresa no ranking da ANEEL, atuando em um ou mais critérios dentre os definidos pelo órgão regulador do setor elétrico, critérios cujo desempenho individual pode ser verificado pela análise do plano Gaia.

\section{Considerações Finais}

Este trabalho teve como objetivo ordenar as concessionárias de distribuição de energia de acordo com o risco de perda de capacidade operacional e econômico-financeira, para isso foram necessárias as seguintes etapas i) identificar os principais critérios de avaliação econômico-financeira, técnico-operacional e social; ii) identificar as principais alternativas de atuação, a fim de evitar situações de excepcionalidade; iii) identificar a racionalidade do processo decisório; e iv) desenvolver a modelagem multicritério com base nas problemáticas de ordenação das concessionárias de distribuição de acordo com o risco de perda a fim de direcioná-las para ações pertinentes e evitar situações de excepcionalidade. A fim de atingir tais objetivos foi realizado um estudo de caso na ANEEL, no âmbito das superintendências SFF, SRD, SGT e SMA, cujos dados foram analisados com o apoio do método Promethée.

Os critérios foram inicialmente identificados durante o estudo dos processos de flexibilização regulatória, a partir dos argumentos das empresas e das análises realizadas pelas áreas técnicas da Agência. Eles foram refinados durante as entrevistas com os decisores, momento em que se pôde selecionar os principais indicadores técnico-operacionais, econômicos financeiros, sociais e de satisfação. As alternativas de atuação identificadas são as atualmente utilizadas pela Agência, que consistem na publicação do ranking e no direcionamento das ações de fiscalização com base na ordem encontrada.

A racionalidade do processo decisório foi identificada por meio de entrevistas com colaboradores das Superintendências que subsidiam as decisões da Diretoria Colegiada da ANEEL. A modelagem proposta possibilitou identificar as empresas que possuem situação mais crítica considerando os critérios e parâmetros definidos nas entrevistas com os decisores.

O trabalho limitou-se a ordenar as empresas, visto que a classificação em faixas de risco traria uma dificuldade de definição dos limites entre as classes, pois a excepcionalidade dos casos de flexibilização regulatória pode levar a uma grande imprecisão. Para fins da pesquisa foram incluídos apenas 6 critérios, de cerca de 100 identificados no estudo. Ademais, do total de 63 concessionárias foi analisada uma amostra com 
10, a fim de adequações à versão acadêmica do software Visual PROMETHEE.

Trabalhos futuros poderão classificar as empresas em categorias de risco, já que o simples ordenamento não tem essa capacidade, pois, apesar de ordenadas, as empresas podem estar na mesma categoria de risco. Da mesma forma, poderão ser realizadas análises em separado para as distribuidoras de energia em regime público e privadas, e dentre essas últimas, separar as que pertencem a um grupo controlador capaz de fazer aportes para investimento na qualidade das que operam por conta própria.

Do ponto de vista prático, apresenta uma ferramenta de decisão que considere vários critérios simultaneamente, no entanto, caso a ANEEL decida oficializar o ranking AMD como subsídio para a análise econômico-financeira das distribuidoras, será também imprescindível que os pesos para os critérios sejam objeto de ampla discussão e posterior normatização. Do ponto de vista acadêmico, o trabalho faz uma inédita aplicação da abordagem AMD, em uma agência pública de regulação.

\section{REFERÊNCIAS}

ANEEL. RIT- Relatório de informações trimestrais. Revisão 6.5. Brasília: ANEEL, 2010. http://www2.aneel.gov.br/aplicacoes/leitura_arquivo/arquivos/RIT\%202010\%20\%20Manual\%20de\%20Preenchimento\%20V6-5.pdf. Acesso: 15 abr. 2017.

Consulta Pública no 015/2014. Obter subsídios à formalização e ao aprimoramento da fiscalização do equilíbrio econômico e financeiro das distribuidoras de energia elétrica, compreendendo a instituição de indicadores públicos de sustentabilidade. Brasília: ANEEL, 2014a. Disponível em http://www2.aneel.gov.br/aplicacoes/consulta_publica/detalhes_consulta.cfm?IdConsultaPublica=266.

Acesso: 14 abr. 2017.

A Missão, a visão e os valores da ANEEL. Brasília: ANEEL, 2015a. Disponível em: http://www.aneel.gov.br/missao-e-visao. Acesso: 09 abr. 2017.

Metodologia IASC. Brasília: ANEEL, 2015b. Disponível em: http://www.aneel.gov.br/metodologia-iasc. Acesso: 15 abr. 2017.

Nota Técnica no 217/2015-SFE/ANEEL. Metodologia para o monitoramento contínuo e diagnóstico técnico preventivo das Distribuidoras e das Transmissoras de Energia Elétrica. Brasília: ANEEL, 2015c. Documento 48534.005991/2015-00. Disponível (mediante cadastro) em http://www.aneel.gov.br/consulta-processual.

PRODIST - Procedimentos de distribuição de energia elétrica no sistema elétrico nacional. Módulo 7 - Cálculo de Perdas na Distribuição. Revisão 4. Brasília: ANEEL, 2015d (atualização). Disponível em http://www.aneel.gov.br/modulo-7. Acesso: 15 abr. 2017.

PRORET - Procedimentos de Regulação Tarifária. Módulo 8.1 - Revisão Tarifária Periódica. Revisão 2. Brasília: ANEEL, 2016a (atualização). Disponível em http://www.aneel.gov.br/documents/654800/14861604/Subm\%C3\%B3dulo+8.1+V4.pdf/. Acesso: 10 abr. 2017.

Resolução Normativa n. 748, de 29 de novembro de 2016. Estabelece os termos e condições para a prestação do serviço público de distribuição de energia elétrica por Distribuidora Designada, nos termos do art. $9^{\circ}$ da Lei n. 12.783, de 11 de janeiro de 2013 e da Portaria ${ }^{\circ} 388$, de 26 de julho de 2016-MME e dá outras providências. Brasília: ANEEL, 2016b. Disponível em: http://www2.aneel.gov.br/cedoc/ren2016748.pdf. Acesso: 15 abr. 2017.

Disponível

Relatório Pesquisa IASC 2016: Brasil, Categorias e Distribuidoras. Brasília: ANEEL, 2016c. http://www.aneel.gov.br/documents/655804/14966747/relatorio iasc 2016 vs final_web_12.compressed.pdf . Acesso: 14 abr. 2017.

Nota Técnica no 023/2017-SRD/ANEEL. Indicador de Desempenho Global de Continuidade de 
2016. Brasília: ANEEL, 2017a. Disponível em http:/www.aneel.gov.br/documents/656827/14864125/Nota+T\%C3\%A9cnica+0023+2017+Ranking+2016/9f 98f718-f6d4-8bb3-2e9a-de596ec7463c. Acesso: 14 abr. 2017.

PRODIST - Procedimentos de Distribuição de Energia Elétrica no Sistema Elétrico Nacional. Módulo 8 - Qualidade da Energia Elétrica. Revisão 8. Brasília: ANEEL, 2017b (atualização). Disponível em http://www.aneel.gov.br/modulo-8. Acesso: 9 abr. 2017.

BELTON, Valerie; STEWART, Theodor. Multiple Criteria Decision Analysis: An Integrated Approach. New York: Springer International Publishing LLC, 2002. 343 p.

BONATTI, Rogério Amaral e BARACHO, Renata Maria Abrantes. A Gestão da informação e o processo decisório no setor energético: mensuração de critérios e alternativas. In Pesquisa Brasileira. em Ciência. da Informação e Biblioteconomia. João Pessoa, v. 10, n. 1, p. 237-249, 2015.

BRANS, Jean-Pierre; MARESCHAL, Bertrand. Prométhée-Gaia: une méthodologie d'aide à la décision en présence de critères multiples. Bruxelas: Éditions de l'Université de Bruxelles, 2002.

CINELLI, Marco et al. How to Support the Application of Multiple Criteria Decision Analysis? Let Us Start with a Comprehensive Taxonomy. Omega, p. 102261, 2020.

CLEMENTE, Tharcylla Rebecca Negreiros et al. Aplicação do PROMETHEE-ROC na priorização de tecnologias críticas para a geração de energia. In XXXV Encontro Nacional de Engenharia de Produção. Fortaleza: 2015. 13p.

de ALMEIDA, AT de; COSTA, A. P. C. S. Aplicações com métodos multicritério de apoio à decisão. Recife: Editora Universitária, 2003.

de ALMEIDA, Adiel Teixeira de. Processo de decisão nas organizações. São Paulo: Ed. Atlas, 2013. 251 p.

de ALMEIDA, Adiel Teixeira de e COSTA, Ana Paula Cabral Seixas. Modelo de decisão multicritério para priorização de sistemas de informação com base no método PROMETHEE. In Gestão \& Produção, v.9, n.2, p.201-214, ago. 2002.

FITTIPALDI, Eduardo Henrique Diniz et al. Comercialização de energia elétrica em um mercado competitivo: um problema de decisão multicritério. In: Seminário de Planejamento Econômico-Financeiro do Setor Elétrico. Brasília: CHESF, 2000. v. 1, p. 1-8.

GARCEZ, Thalles Vitelli e de ALMEIDA, Adiel Teixeira. Avaliação de Risco multidimensional de sistemas subterrâneos de distribuição de energia elétrica. In XLV Simpósio Brasileiro de Pesquisa Operacional. Natal, RN: 2013, pp. 331-342.

GONÇALVES, Cristiane Vitório. Modicidade tarifária como direito de acesso ao serviço público. Revista Jus Navigandi, ISSN 1518-4862, Teresina, ano 18, n. 3732, 19 set. 2013.

GUARNIERI, Patricia. Síntese dos Principais Critérios, Métodos e Subproblemas da Seleção de Fornecedores Multicritério. Revista de Administração Contemporânea, vol.19, n.1, pp.1-25. Rio de Janeiro: ANPAD, 2015.

JANNUZZI, Paulo de Martino et al. Análise Multicritério e Tomada de Decisão em Políticas Públicas: Aspectos Metodológicos, Aplicativo Operacional e Aplicações. Informática Pública, ano 11 (1) pp. 69 - 87, 2009 .

LOPEZ, Hipólito Marcelo Losada e de ALMEIDA, Adiel Teixeira de. Utilizando PROMETHEE V para seleção de portfólio de projetos de uma empresa de energia elétrica. Production, v. 24, n. 3, p. 559-571, 2014.

MACEDO, Perseu Padre de et al. Modelo de Classificação para Substituição de Motores Industriais para o Alcance da Eficiência Energética. Salvador, 2014. 9p. 
MARESCHAL, Bertrand. Visual PROMETHEE 1.4 Manual. Bruxelas (Bélgica): VPSolutions, 2013. 192p.

MOHAMMADI, Majid; REZAEI, Jafar. Ensemble Ranking: Aggregation of rankings produced by different multi-criteria decision-making methods. Omega, p. 102254, 2020.

PRESIDÊNCIA DA REPÚBLICA. Lei no. 9.427/1996: Institui a Agência Nacional de Energia Elétrica ANEEL, disciplina o regime das concessões de serviços públicos de energia elétrica e dá outras providências. Brasília, 1996.

PRESIDÊNCIA DA REPÚBLICA. Decreto nº. 2.335/1997: Constitui a Agência Nacional de Energia Elétrica -ANEEL, autarquia sob regime especial, aprova sua Estrutura Regimental e o Quadro Demonstrativo dos Cargos em Comissão e Funções de Confiança e dá outras providências. Brasília, 1997.

SCHMITZ, William Ismael et al. Estratégia Energética e Socioambiental na Gestão Pública com aplicação dos métodos AHP e PROMETHEE. Santa Maria/RS, 2016. 16p.

SILVA, Sandro Felinto da, e de ALMEIDA, Adiel Teixeira. Modelo multicritério para ordenação dos pontos monitorados de um sistema elétrico com base nos métodos SMARTS/SMARTER. In Seminário Nacional de Produção e Transmissão de Energia Elétrica. Rio de Janeiro: 2007. 7p. 